\title{
Practical Application of Cloud Service Evaluation Index System
}

\author{
Cong Cheng ${ }^{1}$ and Zehua Niu ${ }^{2}$ \\ ${ }^{1}$ Information Center, Beijing Polytechnic College, Beijing, 100042, China \\ ${ }^{2}$ Telecommunication Engineering \&Management, Beijing University of Posts and Telecommunications, Beijing, 102209,China
}

\begin{abstract}
This paper has picked cloud storage services provided by 5 cloud providers that the users are familiar with, investigated, added up and analyzed their 12 service indicators and eventually come up with the total scores and ranking of the service quality for cloud storage. It has creatively come up with a way of measuring the quality of cloud service.
\end{abstract}

Keywords-cloud service; quality of service; index system; cloud storage; credible cloud certification

\section{INTRODUCTION}

In previous studies, we have analyzed cloud evaluation index system and the weight of various indicators and come up with elements (see Table 1) that the users are most concerned about, such as safety, extendibility, performance and so forth. Such indicators may serve as important reference to cloud users when they are choosing cloud services. However, we found that the 12 indicators of each cloud service varied a lot as some showed great safety but had poor performance while some did fine in performance but lacked extendibility. In that case, how do we analyze the quality of cloud service in an objective manner? How to choose a competent enterprise that provides cloud services with relatively higher overall quality indicators? Thus, we have picked cloud storage with relatively larger user bases and five cloud service providers that everyone is familiar with to analyze the quality of their cloud services.

TABLE I. CLOUD SERVICE QUALITY INDEX SYSTEM \& WEIGHT

\begin{tabular}{|l|l|l|}
\hline $\begin{array}{l}\text { Primary } \\
\text { Indicators }\end{array}$ & Secondary Indicators & Weight \\
\hline \multirow{2}{*}{ Safety } & Safety Level & 0.101846661 \\
\cline { 2 - 3 } & Authorized Access & 0.118821321 \\
\hline Extendibility & Extendibility & 0.025365736 \\
\hline \multirow{2}{*}{ Reliability } & Accuracy & 0.070820104 \\
\cline { 2 - 3 } Performance & Robustness & 0.0702868 \\
\hline \multirow{2}{*}{ Availability } & Throughput & 0.07687635 \\
\cline { 2 - 3 } & Data Management Capacity & 0.103596157 \\
\hline \multirow{2}{*}{$\begin{array}{l}\text { Resource } \\
\text { Utilization }\end{array}$} & Average Fault-Free Time & 0.117174584 \\
\cline { 2 - 3 } Cost & Response Time & 0.13164662 \\
\hline \multirow{2}{*}{$\begin{array}{l}\text { Resource Utilization } \\
\text { Price of Cloud Service } \\
\text { Resource }\end{array}$} & 0.163374276 \\
\cline { 2 - 3 } & Default Fine & 0.015143218 \\
\hline
\end{tabular}

\section{COMPARISON With CREdible Cloud SeRVICE CERTIFICATION INDEXT}

In October 2013, the Chinese government launched certification for credible cloud services and established a cloud service evaluation system to help the users choose safe, reliable cloud services and to promote the healthy and orderly development of the cloud computing market. Its evaluation indicators include 16 indicators such as data safety, service quality and right protection and so on that fall into three categories.

Compared to the index system that our studies proposed, only several indicators, such as safety, service indemnity clause, failure recovery capacity, reliability, among the credible cloud certification indicators are common indicators, and the secondary indicators are not that alike. This is because credible cloud certification focuses more on user experience, its evaluation standards are neither systematic nor comprehensive enough, some critical indicators such as accuracy, response time, resource utilization and average fault-free time are not involved, nor has it focused on the weight of various indicators. Just like the development of cloud computing, credible cloud evaluation system is also heading toward more professional, delicate and sophisticated goals. In fact, compared to credible cloud service certification 1.0, two types of special assessment, operation and performance, have been added to the 2.0 version launched recently, and our project has also served as good reference to it.

Based on the core indicators of credible cloud certification, up till July 2015, 46 cloud service providers and 96 cloud services had already passed the credible cloud service certification, among which altogether 35 cloud services in Group 1 and 2 went through the annual inspection organized by the union in 2015, 31 passed the inspection and their pass rate was 88.6\%; in the evaluation certification for Group 3 and 4 later, 68 enterprises and 125 cloud services took the evaluation and 21 enterprises and 33 cloud services in Group 3 passed the certification, which generated a pass rate of 64\%; 22 enterprises and 32 cloud services in Group 4 also passed the certification and the pass rate turned out to be $43 \%$. It's thus clear that the guarantee for purchasing users will increase as the certification system gets more rigorous and sophisticated. 


\section{Selection of Cloud Storage Service and Quality EVALUATION}

Up till now, credible cloud service certification is capable of evaluating twelve types of cloud services, which basically covers the mainstream service types in the industry at present, including cloud host service, object storage service, cloud database service, cloud engine service, block storage service, cloud cache service, local and global load balance service, cloud distribution service, real-time application service, desktop cloud service and corporate mobile management service. There are nearly 20 cloud service providers in the area of object storage alone. These storage services are very much alike in terms of their functionality and consumers can hardly weigh their pros and cons when trying to pick one.

While we were selecting the objects for quality indicators of cloud service, it was done on the basis of twelve types of services with credible cloud certification. Mutual reinforcing of research and industrial application is what makes it meaningful. So far, the most common cloud services that cloud service provides offer are cloud engine and object storage while the service quality of cloud engine is mostly evaluated by data monitoring. Hence, we decided to use cloud storage service as our object of study. In this paper, we have picked five major cloud service providers, namely Kingsoft, Alibaba, Baidu, Sina and Huawei as our storage objects.

The reason for choosing these five cloud storage is that they are all cloud suppliers with relatively higher brand awareness and larger scale so that most users are familiar with them and their grading would be more objective. And the analysis results would be valuable.

\section{Data Source \& Processing Method}

\section{A. Source of ValidData.}

On the basis of past research and analysis, we graded the 12 indicators, namely safety level, authorized access, extendibility, accuracy, robustness, throughput, data management capacity, average fault-free time, response time, resource utilization and price, in the evaluation index system on a five-class scale of excellent, good, average, poor and bad. The scores for the five classes are 10, 8, 6, 4 and 2, respectively. (See Table 2)

The data collection was mainly done through electronic questionnaire. 50 questionnaires were handed out for this study and only those on which each indicator was graded and the total score was no greater or less than the index score were counted as valid questionnaires. Those on which all indicators got a perfect score (10 points) or the lowest score ( 2 points) were deemed invalid. The ideal objects would be professionals who participated in corporate cloud service certification, business webmaster of application cloud service, etc.
TABLE II. QUESTIONNAIRE FOR QUALITY INDICATORS OF CLOUD STORAGE SERVICE

\begin{tabular}{|l|l|l|l|l|l|}
\hline $\begin{array}{l}\text { Service Cloud Storage } \\
\text { Index Score }\end{array}$ & $\begin{array}{c}\text { Kings } \\
\text { oft }\end{array}$ & $\begin{array}{c}\text { Alibab } \\
\text { a }\end{array}$ & Baidu & Sina & $\begin{array}{c}\text { Huaw } \\
\text { ei }\end{array}$ \\
\hline Safety Level & & & & & \\
\hline Authorized Access & & & & & \\
\hline Extendibility & & & & & \\
\hline Accuracy & & & & & \\
\hline Robustness & & & & & \\
\hline Throughput & & & & & \\
\hline $\begin{array}{l}\text { Data Management } \\
\text { Capacity }\end{array}$ & & & & & \\
\hline $\begin{array}{l}\text { Average Fault-Free } \\
\text { Time }\end{array}$ & & & & & \\
\hline Response Time & & & & & \\
\hline $\begin{array}{l}\text { Resource Utilization } \\
\text { Rate }\end{array}$ & & & & & \\
\hline $\begin{array}{l}\text { Price of Cloud Service } \\
\text { Resources }\end{array}$ & & & & & \\
\hline $\begin{array}{l}\text { Total points of various } \\
\text { indicators }\end{array}$ & & & & & \\
\hline
\end{tabular}

\section{B. Data Processing Method}

The basic idea for data processing is: Calculate the itemized scores for each enterprise's 12 secondary indicators of cloud storage according to the scores given by the experts and the weight of each indicator, and then sort the sum of the scores of the 12 indicators out. Furthermore, we have to work out the mean of each of the 12 indicators for each enterprise's storage service, then work out the total score of each indicator by multiplying the mean with its corresponding weight. The expression[1] is as follows:

$$
\mathrm{S}_{\mathrm{ij}}=\frac{\mathrm{Q}_{\mathrm{j}} \sum_{\mathrm{i}}^{\mathrm{n}} \mathrm{X}_{\mathrm{i}}}{\mathrm{n}}
$$

In the above expression, $\mathrm{Sij}$ is the average score for Indicator $\mathrm{j}$ (value of $\mathrm{j}: 1 \sim 12$ ) of Operator $\mathrm{i}(\mathrm{i}=1,2,3,4,5), \mathrm{Xi}$ is the initial score that the respondents given to each indicator, $n$ is the number of valid questionnaires and $\mathrm{Qj}$ is the weight of Indicator $\mathrm{j}$.

Computation expression[2] that gives the total score of each enterprise's storage object is as follows:

$$
\mathrm{Si}=\sum_{\mathrm{j}=1}^{12} \mathrm{~S}_{\mathrm{ij}}
$$

\section{Results OF THE QUALity OF Five Cloud StORAGE SERVICES}

After carefully adding up each questionnaire and calculating with the cloud service quality index system as well as Expression[1] and Expression[2] above, the total scores for the service quality of the five enterprises' cloud object storage turned out to be: Alibaba (86.3), Kingsoft (84.2), Huawei (83.9), Baidu (86.1) and Sina (85.7).

Although Alibaba and Baidu are not that different in terms of service quality and they have their respective advantages in management and technology, they are obviously better compared to the other three enterprises. For a company whose telecom network equipment, IT equipment and solutions as well as intelligent terminal have already been widely used in 
more than 170 countries and regions around the world, Huawei's cloud storage was obviously paled by comparison, which should be a result of its strategic positioning and campaign in the industry. According to the final results of survey data and statistical analysis, the order for the quality of the 5 cloud services is: Alibaba, Baidu, Sina, Kingsoft and Huawei.

The results will help enterprises with their purchase decisions, let the cloud suppliers learn about their ranking and weakness so as to help them continue to improve themselves and their competitiveness, and also serve as references to policy makers. And of course, the ranking won't always stay the same. As each company adjusts its focus and its technology strength, management service even medium publicity in cloud storage continue to change, its quality of service and ranking would also change accordingly.

\section{CONCLUSION}

First of all, the case study of the paper is based on already established cloud service quality index system as well as the relation and weighting analysis of primary indicators and secondary indicators. In this case, we have picked five cloud service providers that corporate users are familiar with: Alibaba, Baidu, Sina, Huawei and Kingsoft, and surveyed and measured the service quality of their cloud storage products. We worked out the average scores of the 12 secondary indicators of each enterprise's cloud storage service first, used the results to calculate the total scores of the 12 cloud storage indicators, and in the end, ranked the quality of the cloud storage of the enterprises surveyed.

Unfortunately, due to lack of resources, we weren't able to get more information experts to join the survey. How to further integrate resources and gather industrial and corporate strength is exactly the first thing we need to think about and work on.

\section{REFERENCES}

[1] Cheng Cong, Lin Shuolei, Weighting Analysis of Coal Enterprise-Based Cloud Evaluation Index System [J]. Coal Engineering, 2015(9):140-143.

[2] Cheng Cong, Zhou Jianhui, Lin Shuolei, Studies of QoS-Based Cloud Service Evaluation Index System [J]. Journal of Beijing Vocational \& Technical Institute of Industry, 2015(1): 30-34.

[3] Su Wei, Credible Cloud Service Certification System, Telecommunication Network Technology, 2014(4):5-7.

[4] Huang Yun, Qos-Based Cloud Service Evaluation Model \& Applied Research[D], Zhejiang Gongshang University, 2013(1). 